\title{
Sense of Community as a Protective Factor against Long-Term Psychological Effects of Childhood Violence
}

\author{
Emily A. Greenfield \\ Rutgers, The State University of New Jersey \\ Nadine F. Marks \\ University of Wisconsin-Madison
}

\begin{abstract}
This study uses a risk and resilience framework for conceptualizing the long-term effects of childhood family violence on mental health. It examines sense of community as a protective factor against adult psychological distress associated with experiences of physical or psychological violence in childhood from parents. Regression models are estimated using data from the 1995 National Survey of Midlife Development in the United States and from the 1996-97 National Study of Daily Experiences. Reported experiences of frequent psychological violence, regardless of the frequency of physical violence, is found to be positively associated with adult psychological distress. Adults' sense of community is found to moderate the association between reports of both frequent psychological and frequent physical violence in childhood from parents and adult psychological distress.
\end{abstract}

Empirical research on the long-term psychological consequences of childhood family violence, including physical, sexual, and psychological abuse, has accumulated over the past decade (Saunders 2003). Studies using data from clinical, community, and national samples have provided consistent evidence that adults who report having been the target of diverse types of violence in childhood demonstrate poorer mental health, on average, than adults who report not having experienced such violence (e.g., Brown and Moran 1994; Straus and Kantor 1994; Kessler, Davis, and Kendler 1997; Kang et al. 1999; Kang, Deren, and Goldstein 2002; Shaw and Krause 2002; Carlson, McNutt, and Choi 2003; Springer

Social Service Review (March 2010).

(c) 2010 by The University of Chicago. All rights reserved.

0037-7961/2010/8401-0007\$10.00 
et al. 2003). Results from prospective studies based on administrative records of abuse have largely converged with findings based on retrospective reports (Cohen, Brown, and Smailes 2001; Horwitz et al. 2001; Widom, DuMont, and Czaja 2007). Despite these accumulating findings, there is little research on why some adults with histories of childhood family violence do not demonstrate poor mental health. Identifying factors and processes that promote optimal mental health among adults with problematic histories of childhood family violence can offer insights into ways to promote long-term resilience in this population.

Drawing on a risk and resilience framework, as well as on scholarship concerning the mental health benefits of community connectedness, this study examines whether having a strong sense of community in adulthood serves as a protective factor against the long-term mental health risks that stem from childhood experiences of family violence. Sense of community refers to an individual's feelings of belonging, relatedness, mattering, and availability of support within a perceived community (McMillan and Chavis 1986). The study uses data from the 1995 National Survey of Midlife Development in the United States (MIDUS) and from the 1996-97 National Study of Daily Experiences (NSDE). These data enable an exploration of links between experiences of violence in childhood and levels of adult psychological distress. The study specifically investigates whether adult sense of community is a beneficial moderator of deleterious associations between childhood family violence and adult psychological distress.

\section{Theoretical Background}

A risk and resilience framework provides a strong foundation for examining factors that can protect the mental health of adults who experienced family violence in childhood. Resilience, as a theoretical orientation, draws attention to the ways that individuals attain positive outcomes when exposed to significant risk or adversity (Rutter 1990; Garmezy 1993; Masten 2001). Theories from diverse disciplines suggest multiple pathways through which childhood family violence serves as a risk factor for individuals' long-term mental health. These include social-relational, social-cognitive, social-institutional, and neurophysiological pathways (e.g., Finkelhor 1995; Cicchetti and Rogosch 2001; Kendall-Tackett 2002). For example, research on social-institutional pathways suggests that experiences of childhood family violence place adults at heightened risk for homelessness, marital disruptions, and difficulties in school. Such experiences might contribute to adverse mental health outcomes in adulthood among individuals with histories of childhood family violence (Kendall-Tackett 2002). Research on socialcognitive pathways suggests that childhood family violence can lead to an individual's persistent belief that the world is a dangerous place and 
that he or she is unable to manage hardship. This damaged sense of personal mastery might also contribute to negative emotions in adulthood among individuals with histories of childhood family violence (Kendall-Tackett 2002).

Other disciplines provide support for conceptualizing adults' strong sense of community as a protective factor against long-term deleterious associations between childhood family violence and adverse mental health outcomes in adulthood. Émile Durkheim ([1897] 1951), for example, posited that integration with society can promote well-being by providing purpose and meaning. He posited that integration enables individuals to share collective goals and affords them access to group resources, particularly in times of need. John Bowlby (1969) also recognized the potentially unique salience of broad social groups for adults' well-being. He wrote: "A school or college, a work group, a religious group or a political group can come to constitute for many people a subordinate attachment-'figure', and for some people a principal attachment-'figure" (207).

Positive attachment to community, as represented by having a strong sense of community, might protect against some of the processes through which experiences of childhood family violence jeopardize long-term mental health. For example, individuals with strong attachments to their community might derive a sense of mastery or the feeling that they can overcome obstacles, because they perceive themselves as part of a cohesive social network (Hobfoll et al. 2002). Having this sense of mastery can help adults to overcome an impaired sense of mastery that might stem, in part, from experiences of childhood family violence.

\section{Empirical Background}

Many posit that the long-term effects of childhood family violence are unlikely to be universal across all individuals who have experienced it (e.g., U.S. National Research Council Panel 1993; Dufour, Nadeau, and Bertrand 2000; McGloin and Widom 2001). Few studies, however, examine factors that might moderate deleterious associations between childhood family violence and adult mental health. Moreover, several conceptual and methodological limitations characterize much of the research on factors that protect against the long-term effects of childhood family violence. First, most studies on resilience among adults with childhood histories of family violence focus exclusively on childhood sexual abuse (e.g., Wright, Fopma-Loy, and Fischer 2005; Gall et al. 2007; Wright, Crawford, and Sebastian 2007; McClure et al. 2008). These studies direct relatively little attention to physical, psychological, and other types of violence. Second, studies in this area attempt to examine factors that promote mental health by drawing on samples that only include individuals with histories of violence (e.g., Jonzon and Lindblad 2006; 
Banyard and Williams 2007; DuMont, Widom, and Czaja 2007; McClure et al. 2008). No known studies include a comparison group of adults who lack a history of violence. The absence of comparison groups impedes efforts to determine whether a factor promotes positive outcomes specifically in the face of childhood family violence or among all individuals, regardless of whether they experienced childhood family violence.

Despite these limitations, results from previous studies provide preliminary insights into factors in adulthood that can buffer against the longterm psychological effects of childhood family violence. Such factors include the availability and receipt of social support (Jonzon and Lindblad 2006), particularly from an intimate partner (Wright et al. 2005; DuMont et al. 2007); positive feelings about one's self (Jonzon and Lindblad 2006); achieving a sense of mastery through positive relationships with others (Banyard and Williams 2007); and spiritual beliefs and religious coping (Dervic et al. 2006; Gall et al. 2007). Studies have found that among adults with histories of childhood family violence, individuals who have these resources display better functioning, on average, in contrast to those who lack these resources.

Furthermore, few studies examine the mental health benefits that accrue from adults' sense of community among adults in general or among adults with histories of childhood family violence. Several studies provide preliminary evidence that a strong sense of community is positively associated with adult mental health outcomes (Davidson and Cotter 1991; Keyes 1998; Prezza et al. 2001; Hobfoll et al. 2002), but methodological limitations make their conclusions tenuous. These limitations include the use of regional samples and the lack of statistical controls for potentially important covariates.

In some qualitative studies that are based on interviews with women only, adults' sense of community is identified as a protective factor for the mental health of adults with histories of childhood abuse (Valentine and Feinauer 1993; Banyard and Williams 2007; Thomas and Hall 2008). Respondents in these studies cite several ways in which having a strong sense of community serves as a source of resilience in adulthood. For example, a strong sense of community is found to provide adults with social support and the opportunity to positively influence the lives of others. It also is found to provide adults with models of positive relationships, which can enhance mental health.

Although quantitative research has not examined the extent to which sense of community promotes mental health specifically among individuals with histories of family violence, findings from quantitative studies suggest that community participation can promote individuals' mental health in the face of other conditions of risk (Musick et al. 1998; Strawbridge et al. 1998; Koenig and Larson 2001). Together, these findings suggest the importance of examining adults' sense of community 


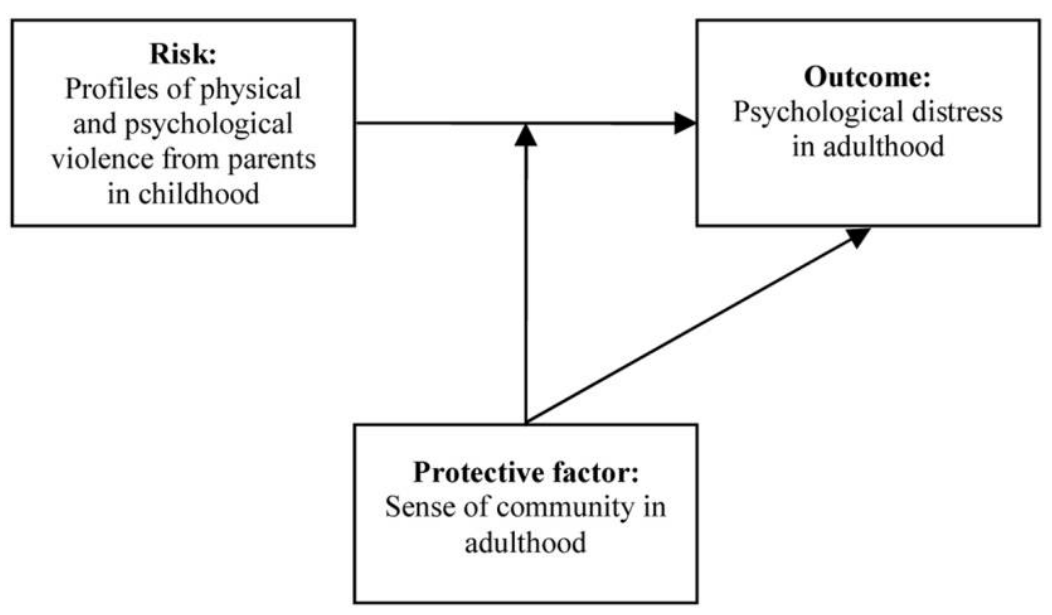

FIG. 1.-Conceptual model of risk and resilience involving linkages among violence from parents in childhood, sense of community in adulthood, and adult psychological distress.

as a potential protective factor against the long-term mental health implications of childhood family violence, particularly within quantitative studies.

\section{Hypotheses}

The current study's conceptual model posits links among multiple types of childhood family violence, adult sense of community, and adult mental health (see fig. 1). Three hypotheses are derived from this model. First, the study hypothesizes that adults who report histories of physical and psychological violence in childhood from parents will report greater levels of psychological distress in adulthood than respondents who do not report histories of physical or psychological violence in childhood from parents. Second, the study posits that sense of community will be inversely associated with psychological distress in adulthood, such that a stronger sense of community will be associated with less distress. Third, the study hypothesizes that sense of community will beneficially moderate deleterious associations between experiences of childhood family violence and adult psychological distress.

\section{Method}

Data

Most data for this study come from the 1995 MIDUS national probability sample, which includes English-speaking, noninstitutionalized adults 
who were between the ages of 25 and 74 in 1995. The sample was obtained through random-digit dialing. Selection probabilities were used to select participants from households to ensure an adequate sample distribution on the cross-classification of age and gender. Selected respondents then participated in a telephone interview that lasted, on average, for 30 minutes. Telephone interview questions largely address respondents' demographic characteristics and medical histories. Respondents who completed the telephone interview were then mailed a selfadministered questionnaire that focuses also on respondents' health as well as psychological factors and social relationships. In the MIDUS sample, a total of 3,024 respondents completed both the telephone survey and the self-administered questionnaire in 1995 (60.8 percent response rate; Brim, Ryff, and Kessler 2004). For a detailed technical report regarding the MIDUS study, see http://midmac.med.harvard.edu/tech.html.

To assess this study's dependent variable (psychological distress) at an occasion subsequent to the assessment of this study's independent variables (childhood family violence and sense of community), this study also uses data from the 1996-97 NSDE. Among the MIDUS sample respondents who completed both the telephone interview and selfadministered questionnaire, 1,242 were randomly selected to participate in the NSDE between March 1996 and March 1997. Of these, 1,031 respondents participated (83 percent response rate; Charles and $\mathrm{Al}-$ meida 2006). The NSDE respondents completed brief telephone interviews regarding their daily experiences on each of eight consecutive evenings.

\section{Measures}

Psychological distress.-A scale new to the NSDE measured psychological distress. This scale was developed from several well-known and validated instruments (see Neupert, Almeida, and Charles 2007, for a discussion). On each night of the study, respondents were asked to rate on a five-point scale $(1=$ all of the time; $5=$ none of the time $)$ how much of the time that day they felt $(a)$ depressed, $(b)$ so sad nothing could cheer them up, $(c)$ nervous, $(d)$ restless or fidgety, $(e)$ hopeless, $(f)$ that everything was an effort, $(g)$ worthless, and $(h)$ tired out for no good reason. Scores on the items across each day of the study were reverse coded, summed, and then standardized at the sample mean, such that higher scores indicated more psychological distress. Cronbach's alpha for this index was .85 across the 8 days. Table 1 presents descriptive statistics for this and all other variables.

Profiles of physical and psychological violence in childhood from parents.Similar to most research on the long-term consequences of childhood family violence (Widom, Raphael, and DuMont 2004), this study uses participants' retrospective reports to assess childhood family violence. 
Table 1

Descriptives for Analytic Variables

\begin{tabular}{|c|c|c|c|}
\hline Variable & Mean* & SD & Range \\
\hline Psychological distress in adulthood & .00 & 1.00 & $-.79-8.53$ \\
\hline \multicolumn{4}{|l|}{$\begin{array}{l}\text { Profiles of violence in childhood from } \\
\text { parents: }\end{array}$} \\
\hline Never physical and never psychological & .25 & .43 & $.00-1.00$ \\
\hline \multicolumn{4}{|l|}{ One type of violence only: } \\
\hline Rare physical only & .08 & .27 & $.00-1.00$ \\
\hline Rare psychological only & .10 & .30 & $.00-1.00$ \\
\hline Frequent physical only & .02 & .13 & $.00-1.00$ \\
\hline Frequent psychological only & .05 & .21 & $.00-1.00$ \\
\hline \multicolumn{4}{|l|}{ Both types of violence: } \\
\hline Rare physical and rare psychological & .15 & .36 & $.00-1.00$ \\
\hline Rare physical and frequent & & 20 & \\
\hline Frequent physical and rare & .10 & .00 & $.00-1.00$ \\
\hline psychological & .04 & .19 & $.00-1.00$ \\
\hline Frequent physical and frequent & & & \\
\hline psychological & .22 & .41 & $.00-1.00$ \\
\hline Adult sense of community & .00 & 1.00 & $-2.53-1.60$ \\
\hline \multicolumn{4}{|l|}{ Covariates: } \\
\hline \multicolumn{4}{|l|}{ Biological parents together in } \\
\hline Parents' education: & & & $.00-1.00$ \\
\hline$<12$ years & .22 & .42 & $.00-1.00$ \\
\hline 12 years & .31 & .46 & $.00-1.00$ \\
\hline$>12$ years & .34 & .47 & $.00-1.00$ \\
\hline Missing & .13 & .34 & $.00-1.00$ \\
\hline Age & 47.42 & 13.08 & $25.00-74.00$ \\
\hline Female & .54 & .50 & $.00-1.00$ \\
\hline \multicolumn{4}{|l|}{ Race or ethnicity: } \\
\hline White & .86 & .34 & $.00-1.00$ \\
\hline Black & .05 & .22 & $.00-1.00$ \\
\hline Latino & .05 & .21 & $.00-1.00$ \\
\hline Other race or ethnicity & .04 & .19 & $.00-1.00$ \\
\hline \multicolumn{4}{|l|}{ Respondents' education: } \\
\hline$<12$ years & .07 & .26 & $.00-1.00$ \\
\hline 12 years & .30 & .46 & $.00-1.00$ \\
\hline $13-15$ years & .33 & .47 & $.00-1.00$ \\
\hline $16+$ years & .31 & .46 & $.00-1.00$ \\
\hline Household income (in $\$ 10,000$ units) & 5.59 & 4.84 & $.00-30.00$ \\
\hline Married & .65 & .48 & $.00-1.00$ \\
\hline Functional health & 2.51 & 2.81 & $.00-9.00$ \\
\hline \multicolumn{4}{|l|}{ History of sexual assault: } \\
\hline Yes & .07 & .26 & $.00-1.00$ \\
\hline No & .41 & .49 & $.00-1.00$ \\
\hline Missing & .52 & .50 & $.00-1.00$ \\
\hline
\end{tabular}

Note. - Data are from the 1995 National Survey of Midlife Development in the United States (MIDUS), with the exception of the measure of psychological distress, which was measured in the 1996-97 National Study of Daily Experiences.

* Means for dichotomous variables are reported as proportions. 
In the self-administered questionnaire of the MIDUS, respondents were presented with a series of items from a modified version of the Conflict Tactics Scales (CTS; Straus 1979). The CTS, which includes multiple subscales to measure different types of violence, is among the most commonly used indices in the field of family violence (Straus et al. 1998). Respondents are introduced to the series of items on childhood family violence as "three lists of things that happen to some children" (MacArthur Midlife Research Network n.d., 32). One list refers to acts of psychological violence, including "insulted you or swore at you; sulked or refused to talk to you; stomped out of the room; did or said something to spite you; threatened to hit you; smashed or kicked something in anger" (32). Two lists refer to acts of physical violence; one includes "pushed, grabbed, or shoved you; slapped you; threw something at you" (32). The other includes "kicked, bit, or hit you with a fist; hit or tried to hit you with something; beat you up; choked you; burned or scalded you" (33). Participants were asked to indicate the extent to which their mother or the woman who raised them, as well as their father or the man who raised them, engaged in any of the acts on each list. Respondents selected one of five response options: "never," "rarely," "sometimes," "often," or "does not apply" (32-33).

Responses to the six items (one referring to each of the three lists of violence by one of two parents) were reconfigured in several ways before respondents were classified into a profile of childhood family violence. First, the researchers excluded from the analysis the 17 respondents who reported that no list of violence applies to either of their parents. This was done to limit the sample to all respondents who were in a position to experience violence from parents. Otherwise, responses of "does not apply" to particular items were coded as "never" if the respondent provided a valid response to at least one other item regarding a particular type of violence by a given parent. Second, although the two lists of physical violence in the self-administered questionnaire were originally intended to distinguish between acts of moderate and severe physical violence, the authors of the CTS revised the original instrument (after the MIDUS instrument already was finalized), given concerns over the items' discriminant validity (see Straus et al. 1998, for a discussion). Because of these concerns, analyses select the higher of respondents' two frequency scores for each list of physical violence and use that score as an indicator of the overall reported frequency of physical violence from parents.

Also, preliminary descriptive analyses suggest that very few respondents reported "never" or "rare" experiences of one type of violence in combination with "often" experiences of the other type of violence. Reports of "sometimes" and "often" are combined into a single category. This is done to ensure that cell sizes are adequate within multivariate models (see the data analytic sequence section below) and to maintain 
distinctions between respondents who reported no violence and those who reported occasional violence, as well as between those reporting occasional violence and those reporting frequent violence. In the current article, the category that combines reports of "sometimes" and "often" violence is described as "frequent."

To code respondents into qualitatively distinct profiles of physical and psychological violence from parents in childhood, respondents are coded into one of eight qualitatively distinct profiles of physical and psychological violence in childhood from either or both parents. The first profile includes respondents who reported that they never experienced physical or psychological violence in childhood from parents. Four additional profiles include only one type of violence at varying levels of frequency. These profiles include (1) rare psychological violence only, (2) rare physical violence only, (3) frequent psychological violence only, and (4) frequent physical violence only. Four additional profiles involve both physical and psychological violence at varying levels of frequency. They include (1) rare physical violence and rare psychological violence, (2) rare physical violence and frequent psychological violence, (3) rare psychological violence and frequent physical violence, and (4) frequent physical violence and frequent psychological violence.

Sense of community.-This study assesses respondents' sense of community with a three-item scale included in the 1995 MIDUS (Keyes 1998). Participants were asked to indicate the extent to which they agree or disagree with each of the following statements on a seven-point continuum ( $1=$ strongly disagree; $7=$ strongly agree): $(a)$ "I feel close to other people in my community," $(b)$ "My community is a source of comfort," and $(c)$ "I don't feel I belong to anything I'd call a community." Responses to item $c$ are reverse coded, and responses across all three items are summed and then standardized at the sample mean. Higher scores indicate higher levels of sense of community. Cronbach's alpha for this index is .73.

\section{Covariates}

Findings from previous studies indicate that a variety of sociodemographic factors are associated with violence against children (e.g., Belsky 1980; Pelton 1994; Berger 2005) and with adults' psychological distress (Ross, Mirowsky, and Goldsteen 1990; Ryff 1995; Mroczek and Kolarz 1998). These factors are important to statistically control for withinmultivariate models that estimate associations between childhood family violence and psychological distress. In this study, dichotomous variables indicate respondents' childhood family structure $(1=$ reported living with both biological parents until age 16), marital status $(1=$ currently married), and gender ( $1=$ female $)$. A multicategorical variable measures parents' highest level of education (less than 12 years, 12 years, 
more than 12 years, and missing data on parents' education). A continuous variable assesses respondents' age. Respondents' race or ethnicity (non-Hispanic white, African American, Latina or Latino, and other race or ethnicity) is measured with a multicategorical variable. Respondents' educational attainment is also measured with a multicategorical variable that is based on respondents' reports of the highest level of school that they completed (less than 12 years, 12 years, 13-15 years, and 16 or more years). A continuous measure captures respondents' household income. Respondents' functional health is measured with a continuous variable created by summing responses to nine items assessing functional health limitations. Because sexual abuse often co-occurs with other types of violence (Higgins and McCabe 2001) and research links childhood sexual abuse to poor adult mental health (Jumper 1995), history of sexual assault is assessed with a multicategorical variable. This variable is based on an item included only at the second wave of data collection in 2005. History of sexual assault includes respondents' reported experiences of sexual assault, reports of no experiences of sexual assault, and missing data on the item regarding sexual assault.

\section{Data Analytic Sequence}

To examine the proposed links among childhood family violence, sense of community, and psychological distress, the analyses estimate multivariate regression models using the ordinary least squares method. All models include the complete block of covariates. Previous research identifies gender differences in associations among family violence, social relationships, and mental health (e.g., Kiecolt-Glaser and Newton 2001; MacMillan et al. 2001). Therefore, preliminary models include terms that estimate the interaction of gender with each of the dichotomous variables for different profiles of violence and with the measure of sense of community. Results from these analyses do not provide evidence for any statistically significant interactions by gender. Accordingly, subsequent analyses analyze data from men and women together.

To test the first hypothesis, which posits deleterious associations between childhood family violence and adult psychological distress, model 1 regresses psychological distress on eight dichotomous variables for the different profiles of physical and psychological violence in childhood from parents. Respondents who report never physical and never psychological violence in childhood from parents serve as the reference category. To examine the second hypothesis, which posits that adult sense of community is inversely related to adult psychological distress, model 1 also includes the measure of adults' sense of community. Model 2 tests the third hypothesis that adults' sense of community serves as a protective factor against deleterious associations between childhood family vio- 
lence and adult psychological distress. Model 2 expands upon model 1 to include multiplicative interaction terms. These terms assess whether adults' sense of community interacts with any of the profiles of violence that the previous model identifies as risk factors for adult psychological distress. A focus only on those profiles found to be positively associated with adult psychological distress follows from conceptualizing resilience as a process that necessitates the presence of risk (Rutter 1990).

\section{Results}

The first hypothesis posits that respondents who report physical or psychological violence from parents in childhood will demonstrate higher levels of psychological distress in adulthood than respondents who report never physical and never psychological violence in childhood from parents. Model 1 in table 2 displays estimates indicating results for this hypothesis. Three profiles of violence are estimated to be associated with adult psychological distress. Each of these three profiles includes respondents who report experiences of frequent psychological violence from parents. More specifically, respondents who report experiencing frequent physical and frequent psychological violence from parents are estimated to have higher levels of adult psychological distress than those who report never physical and never psychological violence $(b=.39$, $p \leq .001)$. Furthermore, in comparison to those who report never physical and never psychological violence, levels of psychological distress are estimated to be higher among those who report rare physical and frequent psychological violence $(b=.22, p \leq .05)$, as well as among those who report frequent psychological violence only $(b=.35, p \leq .05)$. Estimates indicate that other measured profiles of physical and psychological violence are not associated with adult psychological distress to a statistically significant degree.

The second hypothesis predicts that adult sense of community will be inversely related to adult psychological distress. Results for tests of this hypothesis are presented in model 1 in table 2. Estimates indicate that there is an inverse relation, such that a stronger sense of community is correlated with lower levels of adult psychological distress $(b=-.13$, $p \leq .001)$.

The third hypothesis predicts that adult sense of community moderates the associations between childhood family violence and psychological distress in adulthood. Model 2 in table 2 displays results for tests of this hypothesis. Consistent with the hypothesis, the results suggest that adult sense of community beneficially moderates the association of experiences of both frequent physical and frequent psychological violence with psychological distress in adulthood $(b=-.20, p \leq .05)$. Estimates of the interaction terms for the other two violence profiles associated with adult psychological distress (see model 1 in table 2) are 
Table 2

Psychological Distress Regressed on Violence and Sense of Community

\begin{tabular}{|c|c|c|c|c|}
\hline \multirow[b]{2}{*}{ VARIABLE } & \multicolumn{2}{|c|}{ MODEL 1} & \multicolumn{2}{|c|}{ MODEL 2} \\
\hline & $b$ & SE & $b$ & SE \\
\hline \multicolumn{5}{|l|}{ Profiles of violence in childhood from parents: } \\
\hline \multicolumn{5}{|l|}{$\begin{array}{l}\text { Never physical and never psychological } \\
\text { (reference) }\end{array}$} \\
\hline \multicolumn{5}{|l|}{ One type of violence only: } \\
\hline Rare physical only & -.05 & .12 & & \\
\hline Rare psychological only & -.19 & .23 & & \\
\hline Frequent physical only & -.13 & .11 & & \\
\hline Frequent psychological only & $.35^{*}$ & .15 & $.33^{*}$ & .17 \\
\hline \multicolumn{5}{|l|}{ Both types of violence: } \\
\hline Rare physical and rare psychological & .01 & .10 & & \\
\hline Rare physical and frequent psychological & $.22 *$ & .11 & .16 & .13 \\
\hline Frequent physical and rare psychological & -.03 & .17 & & \\
\hline Frequent physical and frequent & & & & \\
\hline psychological & $.39 * * *$ & .09 & $.30 * *$ & .10 \\
\hline Adult sense of community & $-.13^{* * *}$ & .03 & -.10 & .07 \\
\hline \multicolumn{5}{|l|}{ Profiles of violence $\times$ sense of community: ${ }^{a}$} \\
\hline \multicolumn{5}{|l|}{$\begin{array}{l}\text { Never physical and never psychological } \\
\text { (reference) }\end{array}$} \\
\hline \multicolumn{5}{|l|}{ Never physical and rare psychological } \\
\hline Never physical and frequent psychological & & & -.08 & .14 \\
\hline \multicolumn{5}{|l|}{ Rare physical and never psychological } \\
\hline \multicolumn{5}{|l|}{ Rare physical and rare psychological } \\
\hline Rare physical and frequent psychological & & & -.08 & .13 \\
\hline \multicolumn{5}{|l|}{ Frequent physical and never psychological } \\
\hline \multicolumn{5}{|l|}{ Frequent physical and rare psychological } \\
\hline \multicolumn{5}{|l|}{ Frequent physical and frequent } \\
\hline psychological & & & $-.20^{*}$ & .09 \\
\hline Constant & .31 & & $.69 * *$ & \\
\hline$R^{2}$ & .17 & & .22 & \\
\hline Valid $N$ & 961 & & 587 & \\
\hline
\end{tabular}

Note.-Data are from the 1995 National Survey of Midlife Development in the United States (MIDUS), with the exception of the measure of psychological distress, which was measured in the 1996-97 National Study of Daily Experiences. All models include as covariates measures of respondents' parents' highest level of education, respondents' childhood family structure, history of sexual assault, age, gender, and race or ethnicity, as well as several current (at the time of the MIDUS) measures: educational attainment, household income, marital status, and functional health.

${ }^{a}$ Model 2 added interaction terms only with respect to those profiles of physical and psychological violence that were associated with psychological distress at a statistically significant level in model 1.

$* p \leq .05$.

$* * p \leq .01$

$* * * \quad p \leq .001$ (two-tailed). 
in the anticipated direction, but the results do not achieve statistical significance.

To interpret the statistically significant interaction of frequent physical and frequent psychological violence $\times$ sense of community, analyses use estimates from model 2 to calculate predicted scores for four theoretically relevant subgroups of respondents. These subgroups include those who reported (1) never physical and never psychological violence and whose sense of community scores are 1 standard deviation below the sample mean, (2) frequent physical and frequent psychological violence and whose sense of community scores are 1 standard deviation below the sample mean, (3) never physical and never psychological violence and whose sense of community scores are 1 standard deviation above the sample mean, and (4) frequent physical and frequent psychological violence from parents and whose sense of community scores are 1 standard deviation above the sample. The baseline multivariate model used for these computations includes scores for persons at the mean on all other continuous variables and zero on all other categorical variables. Figure 2 displays results from these calculations.

Among respondents at both levels of sense of community, respondents who report experiences of both frequent physical and frequent psychological violence in childhood from parents are estimated to have higher levels of adult psychological distress than respondents who report neither type of violence. The difference in levels of distress between respondents in each of the two profiles is estimated to be smaller among respondents with a high sense of community than among those with a low sense of community. Results from a simple slopes test indicate that, among respondents whose sense of community falls 1 standard deviation below the sample mean, the profile for frequent physical and frequent psychological violence is found to be positively associated with adult psychological distress $(b=.50, p \leq .001)$. Among respondents whose sense of community score is 1 standard deviation above the sample mean, the same profile is not found to be associated with adult psychological distress at a statistically significant level $(b=.11)$. These results provide some support for the third hypothesis, which predicts that adults' sense of community beneficially moderates deleterious links between childhood family violence and adult psychological distress.

\section{Discussion}

This study examines physical and psychological violence in childhood from parents as a risk factor for adults' psychological distress. It also investigates whether adults' sense of community serves as a protective factor against long-term associations of risk. Findings provide evidence that three specific profiles of violence in childhood from par- 


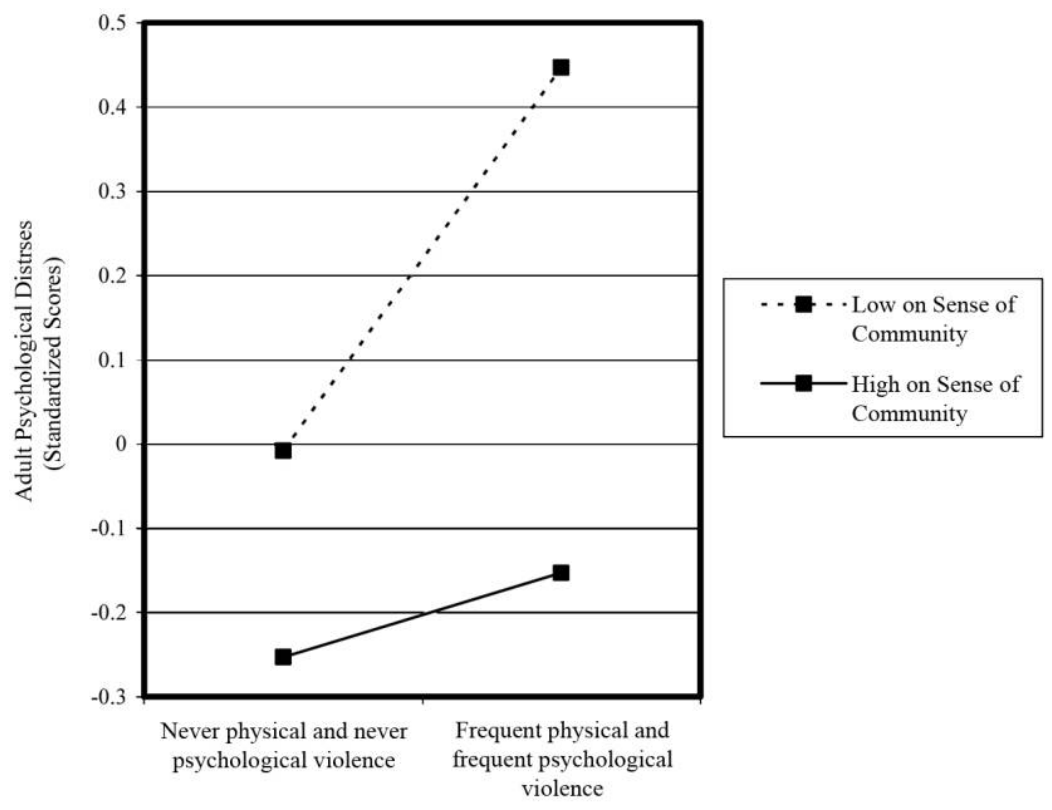

FIG. 2.-Predicted scores of adult psychological distress for respondents at two different levels of sense of community in adulthood who reported (1) never physical and never psychological violence from parents in childhood or (2) frequent physical and frequent psychological violence from parents in childhood y. NoTE.-Childhood family violence and adult sense of community were measured in the 1995 National Survey of Midlife Development in the United States, and adult psychological distress was measured in the 1996-97 National Study of Daily Experiences.

ents pose risk for adult psychological distress. These profiles include experiences of (1) both frequent physical and frequent psychological violence, (2) rare physical and frequent psychological violence, and (3) frequent psychological violence only. These results, taken together, suggest that experiencing psychological violence from parents, and particularly experiencing it frequently, is a powerful risk factor for psychological distress in adulthood. This pattern of results responds to previous calls for greater specificity in defining risk factors within research on the developmental consequences of family violence (e.g., Johnson and Ferraro 2000), as well as within research on resilience more broadly (e.g., Masten et al. 1999).

Results from this study also provide some evidence for processes of protection that help to ameliorate processes through which childhood family violence might jeopardize adult mental health. The results suggest that having a strong sense of community promotes adults' mental health, regardless of histories of family violence in childhood. Sense of community also can protect against risk from associations between some profiles of violence and adult psychological distress. These results are 
congruent with findings from qualitative studies in which adults' connection to community is found to be a factor that can promote longterm resilience among individuals who experienced childhood abuse (Valentine and Feinauer 1993; Banyard and Williams 2007; Thomas and Hall 2008).

It is important to note, however, that results for only one of the profiles of childhood family violence provide evidence for sense of community as a protective factor against adult psychological distress. Adult sense of community is found to moderate the association of risk specifically with respect to the profile for frequent physical and frequent psychological violence. Interaction effects for the two other problematic profiles (i.e., frequent experiences of psychological violence only; rare physical violence and frequent psychological violence) are in the anticipated direction of a protective effect but do not achieve statistical significance. The absence of statistical significance could suggest that the model lacks adequate statistical power; the numbers of respondents who reported no or rare experiences of physical violence in combination with frequent psychological violence are smaller than the number of respondents who reported frequent physical and frequent psychological violence. Nevertheless, conceptual processes could also underlie this pattern of results. The processes through which experiences of frequent physical and frequent psychological violence in childhood undermine adults' mental health might be particularly susceptible to the moderating processes through which adult sense of community promotes mental health. Additional studies are needed to further explore the protection that sense of community provides adults against the mental health disadvantages associated with specific profiles of childhood family violence.

Additional studies are also needed to understand how some individuals with histories of childhood family violence are able to achieve a strong sense of community in adulthood. Also worthy of research attention are the processes through which a strong sense of community promotes mental health among adults with experiences of childhood family violence. Understanding these processes is essential for the development of practices and programs that focus on sense of community as a long-term protective factor.

Processes involving childhood family violence, adult sense of community, and adult mental health are likely complex. Protective resources in adulthood might be, in part, a function of protective resources accumulated in childhood. For example, research finds that the presence of a supportive adult can protect children from some of the negative consequences of abuse (Spaccarelli and Kim 1995). Perhaps this protective factor in childhood allows individuals to enter into relationships as adults that contribute to their strong sense of community, which then affords them mental health advantages. To better elucidate these processes, there is a need for data that are gathered at multiple points 
across the life course and that examine diverse yet specific biopsychosocial domains. Moreover, use of other analytic techniques, such as person-centered approaches (Nurius and Macy 2008), would better address the ways in which risk, vulnerability, protection, and outcomes potentially interact across the life course.

Despite this study's contributions, several features limit full interpretation of results. First, despite this study's inclusion of many statistical controls, the study does not account for such features as genetic factors, other types of childhood family adversities, and other protective factors in adulthood. If taken into account, these features might yield a more complex causal story than the one suggested here. Also, although reports of psychological distress were gathered after the assessments of childhood family violence and adult sense of community, the reported links among childhood family violence, sense of community, and adult psychological distress might, in part, still reflect processes of reverse causality. Individuals' mental health problems might cause them to recall negative interpersonal interactions from childhood. So too, adults' mental health might cause them to report having a strong sense of community. Furthermore, this study examines only one specific aspect of adult mental health: psychological distress. Patterns of links among childhood family violence, sense of community, and adult well-being might differ for other aspects of mental health, such as positive feelings of personal growth. Moreover, individuals who demonstrate resilience through low reported levels of psychological distress in adulthood might not demonstrate resilience in other dimensions of adult functioning (see Chambers and Belicki 1998 for a discussion), which this study did not examine.

Despite these limitations, the current findings provide some evidence that sense of community in adulthood serves as a protective factor against the long-term mental health risks of physical and psychological violence in childhood. In general, results from this study suggest the continued importance of specifying risk factors and examining protective factors that account for differences in mental health among adults with histories of childhood family violence. By examining specific conditions of risk and exploring processes of protection, researchers, practitioners, policy makers, and individuals can improve efforts to optimize the present and future well-being of adults with histories of childhood family violence.

\section{References}

Banyard, Victoria L., and Linda M. Williams. 2007. "Women's Voices on Recovery: A MultiMethod Study of the Complexity of Recovery from Child Sexual Abuse." Child Abuse and Neglect 31 (3): 275-90.

Belsky, Jay. 1980. "Child Maltreatment: An Ecological Integration." American Psychologist 35 (4): 320-35. 
Berger, Lawrence M. 2005. "Income, Family Characteristics, and Physical Violence toward Children." Child Abuse and Neglect 29 (2): 107-33.

Bowlby, John. 1969. Attachment. Vol. 1 of Attachment and Loss. New York: Basic.

Brim, Orville Gilbert, Carol D. Ryff, and Ronald C. Kessler. 2004. "The MIDUS National Survey: An Overview." 1-34 in How Healthy Are We? A National Study of Well-Being at Midlife, edited by Orville G. Brim, Carol D. Ryff, and Ronald C. Kessler. Chicago: University of Chicago Press.

Brown, George W., and Patricia Moran. 1994. "Clinical and Psychosocial Origins of Chronic Depressive Episodes: A Community Survey." British Journal of Psychiatry 165 (4): 447-56.

Carlson, Bonnie E., Louise-Anne McNutt, and Deborah Y. Choi. 2003. "Childhood and Adult Abuse among Women in Primary Health Care: Effects on Mental Health." Journal of Interpersonal Violence 18 (8): 924-41.

Chambers, Elisha, and Kathy Belicki. 1998. "Using Sleep Dysfunction to Explore the Nature of Resilience in Adult Survivors of Childhood Abuse or Trauma." Child Abuse and Neglect 22 (8): 753-58.

Charles, Susan T., and David M. Almeida. 2006. "Daily Reports of Symptoms and Negative Affect: Not All Symptoms Are the Same." Psychology and Health 21 (1): 1-17.

Cicchetti, Dante, and Fred A. Rogosch. 2001. "The Impact of Child Maltreatment and Psychopathology on Neuroendocrine Functioning." Development and Psychopathology 13 (4): 783-804.

Cohen, Patricia, Jocelyn Brown, and Elizabeth Smailes. 2001. "Child Abuse and Neglect and the Development of Mental Disorders in the General Population." Development and Psychopathology 13 (4): 981-99.

Davidson, William B., and Patrick R. Cotter. 1991. "The Relationship between Sense of Community and Subjective Well-Being: A First Look." Journal of Community Psychology 19 (3): 246-53.

Dervic, Kanita, Michael F. Grunebaum, Ainsley K. Burke, J. John Mann, and Maria A. Oquendo. 2006. "Protective Factors against Suicidal Behavior in Depressed Adults Reporting Childhood Abuse." Journal of Nervous and Mental Disease 194 (12): 971-74.

Dufour, Magali H., Louise Nadeau, and Karine Bertrand. 2000. "Resilience Factors in the Victims of Sexual Abuse: State of Affairs.” Child Abuse and Neglect 24 (6): 781-97.

DuMont, Kimberly A., Cathy Spatz Widom, and Sally J. Czaja. 2007. "Predictors of Resilience in Abused and Neglected Children Grown-Up: The Role of Individual and Neighborhood Characteristics.” Child Abuse and Neglect 31 (3): 255-74.

Durkheim, Émile. (1897) 1951. Suicide: A Study in Sociology. Trans. John A. Spaulding and George Simpson. Glencoe, IL: Free Press.

Finkelhor, David. 1995. "The Victimization of Children: A Developmental Perspective." American Journal of Orthopsychiatry 65 (2): 177-93.

Gall, Terry, Viola Basque, Marizete Damasceno-Scott, and Gerard Vardy. 2007. "Spirituality and the Current Adjustment of Adult Survivors of Childhood Sexual Abuse." Journal for the Scientific Study of Religion 46 (1): 101-17.

Garmezy, Norman. 1993. "Children in Poverty: Resilience despite Risk." Psychiatry: Interpersonal and Biological Processes 56 (1): 127-36.

Higgins, Daryl J., and Marita P. McCabe. 2001. "Multiple Forms of Child Abuse and Neglect: Adult Retrospective Reports." Aggression and Violent Behavior 6 (6): 547-78.

Hobfoll, Stevan E., Anita Jackson, Ivonne Hobfoll, Charles A. Pierce, and Sara Young. 2002. "The Impact of Communal-Mastery versus Self-Mastery on Emotional Outcomes during Stressful Conditions: A Prospective Study of Native American Women.” American Journal of Community Psychology 30 (6): 853-71.

Horwitz, Allan V., Cathy Spatz Widom, Julie McLaughlin, and Helene Raskin White. 2001. "The Impact of Childhood Abuse and Neglect on Adult Mental Health: A Prospective Study." Journal of Health and Social Behavior 42 (2): 184-201.

Johnson, Michael P., and Kathleen J. Ferraro. 2000. "Research on Domestic Violence in the 1990s: Making Distinctions.” Journal of Marriage and the Family 62 (4): 948-63.

Jonzon, Eva, and Frank Lindblad. 2006. "Risk Factors and Protective Factors in Relation to Subjective Health among Adult Female Victims of Child Sexual Abuse." Child Abuse and Neglect 30 (2): 127-43.

Jumper, Shan A. 1995. "A Meta-Analysis of the Relationship of Child Sexual Abuse to Adult Psychological Adjustment." Child Abuse and Neglect 19 (6): 715-28.

Kang, Sung-Yeon, Sherry Deren, and Marjorie F. Goldstein. 2002. "Relationships between 
Childhood Abuse and Neglect Experience and HIV Risk Behaviors among Methadone Treatment Drop-Outs." Child Abuse and Neglect 26 (12): 1275-89.

Kang, Sung-Yeon, Stephen Magura, Alexandre Laudet, and Shirley Whitney. 1999. "Adverse Effect of Child Abuse Victimization among Substance-Using Women in Treatment." Journal of Interpersonal Violence 14 (6): 657-70.

Kendall-Tackett, Kathleen. 2002. "The Health Effects of Childhood Abuse: Four Pathways by Which Abuse Can Influence Health." Child Abuse and Neglect 26 (6-7): 715-29.

Kessler, Ronald C., C. G. Davis, and Kenneth S. Kendler. 1997. "Childhood Adversity and Adult Psychiatric Disorder in the U.S. National Comorbidity Survey." Psychological Medicine 27 (5): 1101-19.

Keyes, Corey Lee M. 1998. "Social Well-Being." Social Psychology Quarterly 61 (2): 121-40. Kiecolt-Glaser, Janice K., and Tamara L. Newton. 2001. "Marriage and Health: His and Hers." Psychological Bulletin 127 (4): 472-503.

Koenig, Harold G., and David B. Larson. 2001. "Religion and Mental Health: Evidence for an Association." International Review of Psychiatry 13 (2): 67-78.

MacArthur Midlife Research Network. n.d. "Self-Administered Questionnaire 1 and 2 (SAQs)." University of Wisconsin-Madison. http://www.midus.wisc.edu/midus1/mail _parts_1_2.pdf (accessed April 11, 2010).

MacMillan, Harriet L., Jan E. Fleming, David L. Streiner, Elizabeth Lin, Michael H. Boyle, Ellen Jamieson, Eric K. Duku, et al. 2001. "Childhood Abuse and Lifetime Psychopathology in a Community Sample." American Journal of Psychiatry 158 (11): 1878-83.

Masten, Ann S. 2001. "Ordinary Magic: Resilience Processes in Development." American Psychologist 56 (3): 227-38.

Masten, Ann S., Jon J. Hubbard, Scott D. Gest, Auke Tellegen, Norman Garmezy, and Marylouise Ramirez. 1999. "Competence in the Context of Adversity: Pathways to Resilience and Maladaptation from Childhood to Late Adolescence." Development and Psychopathology 11 (1): 143-69.

McClure, Faith H., David V. Chavez, Mark D. Agars, M. Jean Peacock, and Amy Matosian. 2008. "Resilience in Sexually Abused Women: Risk and Protective Factors." Journal of Family Violence 23 (2): 81-88.

McGloin, Jean Marie, and Cathy Spatz Widom. 2001. "Resilience among Abused and Neglected Children Grown Up." Development and Psychopathology 13 (4): 1021-38.

McMillan, David W., and David M. Chavis. 1986. "Sense of Community: A Definition and Theory." American Journal of Community Psychology 14 (1): 6-23.

Mroczek, Daniel K., and Christian M. Kolarz. 1998. "The Effect of Age on Positive and Negative Affect: A Developmental Perspective on Happiness." Journal of Personality and Social Psychology 75 (5): 1333-49.

Musick, Marc A., Harold G. Koenig, Judith C. Hays, and Harvey Jay Cohen. 1998. "Cancer, Religious Activity, and Depressive Symptomatology among a Sample of Community Dwelling Elderly." Journals of Gerontology: Series B; Psychological Sciences and Social Sciences 53 (4): S218-S227.

Neupert, Shevaun D., David M. Almeida, and Susan T. Charles. 2007. "Age Differences in Reactivity to Daily Stressors: The Role of Personal Control." Journals of Gerontology: Series B; Psychological Sciences and Social Sciences 62 (4): P216-P225.

Nurius, Paula S., and Rebecca J. Macy. 2008. "Heterogeneity among Violence-Exposed Women: Applying Person-Oriented Research Methods." Journal of Interpersonal Violence 23 (3): 389-415.

Pelton, Leroy H. 1994. "The Role of Material Factors in Child Abuse and Neglect." 131-81 in Protecting Children from Abuse and Neglect: Foundations for a New Strategy, edited by Gary B. Melton and Frank D. Barry. New York: Guilford.

Prezza, Miretta, Matilde Amici, Tiziana Roberti, and Gloria Tedeschi. 2001. "Sense of Community Referred to the Whole Town: Its Relations with Neighboring, Loneliness, Life Satisfaction, and Area of Residence." Journal of Community Psychology 29 (1): 29-52.

Ross, Catherine E., John Mirowsky, and Karen Goldsteen. 1990. "The Impact of the Family on Health: The Decade in Review." Journal of Marriage and the Family 52 (4): 1059-78.

Rutter, Michael. 1990. "Psychosocial Resilience and Protective Mechanisms." 181-214 in Risk and Protective Factors in the Development of Psychopathology, edited by Jon E. Rolf, Ann S. Masten, Dante Cicchetti, Keith H. Nuechterlein, and Sheldon Weintraub. New York: Cambridge University Press. 
Ryff, Carol D. 1995. "Psychological Well-Being in Adult Life." Current Directions in Psychological Science 4 (4): 99-104.

Saunders, Benjamin E. 2003. "Understanding Children Exposed to Violence." Journal of Interpersonal Violence 18 (4): 356-76.

Shaw, Benjamin A., and Neal Krause. 2002. "Exposure to Physical Violence during Childhood, Aging, and Health." Journal of Aging and Health 14 (4): 467-94.

Spaccarelli, Steve, and Soni Kim. 1995. "Resilience Criteria and Factors Associated with Resilience in Sexually Abused Girls." Child Abuse and Neglect 19 (9): 1171-82.

Springer, Kristen W., Jennifer Sheridan, Daphne Kuo, and Molly Carnes. 2003. "The LongTerm Health Outcomes of Childhood Abuse: An Overview and a Call to Action." Journal of General Internal Medicine 18 (10): 864-70.

Straus, Murray. 1979. "Measuring Intrafamily Conflict and Violence: The Conflict Tactics (CT) Scales." Journal of Marriage and the Family 41 (1): 75-88.

Straus, Murray A., Sherry L. Hamby, David Finkelhor, David W. Moore, and Desmond Runyan. 1998. "Identification of Child Maltreatment with the Parent-Child Conflict Tactics Scales: Development and Psychometric Data for a National Sample of American Parents." Child Abuse and Neglect 22 (4): 249-70.

Straus, Murray A., and Glenda Kaufman Kantor. 1994. "Corporal Punishment of Adolescents by Parents: A Risk Factor in the Epidemiology of Depression, Suicide, Alcohol Abuse, Child Abuse, and Wife Beating." Adolescence 29 (115): 543-61.

Strawbridge, William J., Sarah J. Shema, Richard D. Cohen, Robert E. Roberts, and George A. Kaplan. 1998. "Religiosity Buffers Effects of Some Stressors on Depression but Exacerbates Others." Journals of Gerontology: Series B; Psychological Sciences and Social Sciences 53 (3): S118-S126.

Thomas, Sandra P., and Joanne M. Hall. 2008. "Life Trajectories of Female Child Abuse Survivors Thriving in Adulthood." Qualitative Health Research 18 (2): 149-66.

U.S. National Research Council Panel on Research on Child Abuse and Neglect. 1993. Understanding Child Abuse and Neglect. Washington, DC: National Academy Press.

Valentine, LaNae, and Leslie L. Feinauer. 1993. "Resilience Factors Associated with Female Survivors of Childhood Sexual Abuse." American Journal of Family Therapy 21 (3): 216-24.

Widom, Cathy Spatz, Kimberly DuMont, and Sally J. Czaja. 2007. "A Prospective Investigation of Major Depressive Disorder and Comorbidity in Abused and Neglected Children Grown Up." Archives of General Psychiatry 64 (1): 49-56.

Widom, Cathy Spatz, Karen G. Raphael, and Kimberly A. DuMont. 2004. "The Case for Prospective Longitudinal Studies in Child Maltreatment Research: Commentary on Dube, Williamson, Thompson, Felitti, and Anda." 2004. Child Abuse and Neglect 28 (7): 715-22.

Wright, Margaret O’Dougherty, Emily Crawford, and Katherine Sebastian. 2007. "Positive Resolution of Childhood Sexual Abuse Experiences: The Role of Coping, BenefitFinding and Meaning-Making." Journal of Family Violence 22 (7): 597-608.

Wright, Margaret O'Dougherty, Joan Fopma-Loy, and Stephanie Fischer. 2005. "Multidimensional Assessment of Resilience in Mothers Who Are Child Sexual Abuse Survivors." Child Abuse and Neglect 29 (10): 1173-93. 